\title{
Vascular and morphological features of the corpus luteum 12 to 20 days after timed artificial insemination in dairy cattle
}

\author{
Luiz G. Siqueira, ${ }^{1}$ Eduardo K. Arashiro, ${ }^{2}$ Alberto M. Ghetti, ${ }^{2}$ Eliza D. Souza, ${ }^{1}$ Luiz F. Feres, ${ }^{3}$ Luiz F. Pfeifer, ${ }^{4}$ \\ Jeferson F. Fonseca, ${ }^{5}$ and João H. Viana ${ }^{3,6 *}$ \\ ${ }^{1}$ Embrapa Gado de Leite, Juiz de Fora, MG, Brazil 36038-330 \\ ${ }^{2}$ Universidade Federal Fluminense, Niterói, RJ, Brazil 24230-340 \\ ${ }^{3}$ Universidade Jose do Rosario Vellano, Alfenas, MG, Brazil 37130-000 \\ ${ }^{4}$ Embrapa Rondônia, Porto Velho, RO, Brazil 76815-800 \\ ${ }^{5}$ Embrapa Caprinos e Ovinos, Sobral, CE, Brazil 62010-970 \\ ${ }^{6}$ Embrapa Recursos Genéticos e Biotecnologia, Brasília, DF, Brazil 70770-917
}

\section{ABSTRACT}

Our objective was to retrospectively compare pregnant versus nonpregnant cattle in terms of vascular and morphometric changes in corpora lutea between d 12 and 20 following timed artificial insemination (TAI). Crossbred (Gir $\times$ Holstein) lactating dairy cows $(\mathrm{n}=$ $136)$ and heifers $(\mathrm{n}=111)$ were bred after synchronizing ovulations using an estradiol plus progesterone (P4)-based protocol. Corpus luteum (CL) characteristics (area, echotexture, blood flow) were recorded at 48-h intervals from d 12 to 20 following TAI using an ultrasound equipped with color Doppler. Blood samples were collected to determine CL function (plasma P4). Pregnancy diagnosis was performed at d 30. Quantitative assessment of colored pixels within the CL was performed using ImageJ software (National Institutes of Health, Bethesda, MD) and echotexture was quantified using custom software. Continuous variables such as luteal tissue area (LTA), CL blood flow (CLBF), adjusted CLBF (ratio LTA:CLBF), mean pixel value (MPV), pixel heterogeneity (HETER), and plasma P4 were analyzed retrospectively as repeated measures (d 12 to 20) in pregnant versus nonpregnant females using PROC MIXED (SAS Institute Inc., Cary, NC). Main effects were pregnancy status, day of cycle, and their interaction. Further analyses used only data from d 16, because this was the earliest time point of deviation between CLBF of pregnant and nonpregnant animals. We created quartiles for each variable and calculated the risk of pregnancy within quartile. Differences were determined using the chi-squared test. Plasma P4 was significantly higher in prospective pregnant versus

Received October 15, 2018.

Accepted February 11, 2019.

*Corresponding author: henrique.viana@embrapa.br nonpregnant cattle on d 18 and 20, whereas LTA differed only on d 20. On d 16, CLBF and adjusted CLBF diverged between pregnant and nonpregnant, followed by a progressive reduction in the latter until d 20 . Mean pixel value was not affected by pregnancy status, but HETER was lower on d 20 in pregnant than in nonpregnant cattle. Likelihood of pregnancy increased from quartile (Q)1 (lowest values) to Q4 (highest) of CLBF (Q4 vs. Q1, odds ratio $=32.8,95 \%$ confidence interval: 9.6 to 112.1) and adjusted CLBF [Q4 vs. Q1, odds ratio $=25.4,95 \%$ confidence interval: 8.1 to 80.4 ), whereas a lower risk of pregnancy was observed only for animals within Q1 of plasma P4 [Q4 vs. Q1, odds ratio $=3.1,95 \%$ confidence interval: 1.3 to 7.2 ). Day 16 quartiles of LTA, MPV, and HETER did not affect odds of pregnancy. In conclusion, we identified distinct CLBF patterns as early as $16 \mathrm{~d}$ after TAI and confirmed that CL function is lost by a reduction in blood flow, which precedes physical regression.

Key words: Doppler, ultrasonography, luteolysis, blood flow

\section{INTRODUCTION}

The ultimate goal in cattle reproductive management is the successful establishment of a pregnancy that is carried to term. One of the primary steps to achieve this goal is driven by the early conceptus, which must signal its presence to the dam in a well-orchestrated biological process referred to as maternal recognition of pregnancy (Thatcher et al., 1986; Niswender et al., 2000; Mamo et al., 2012). In cycling cattle, prostaglandin-induced lysis of the corpus luteum (CL; i.e., luteolysis) occurs at approximately d 16 to 20 of the estrous cycle in nonpregnant females (Niswender et al., 1994; Fields and Fields, 1996) and involves a transient increase followed by a dramatic decrease in CL blood flow (Girsh et al., 1995; Plendl, 2000; Fraser and Wulff, 2003) in response 
to $\mathrm{PGF}_{2 \alpha}$ (Wiltbank et al., 1995; Acosta et al., 2002, Ginther et al., 2007).

Previous studies have used B-mode, grayscale ultrasonography to demonstrate that functional luteolysis (loss of function) precedes structural luteolysis (loss of tissue volume) by at least $24 \mathrm{~h}$ after exogenous treatment with $\mathrm{PGF}_{2 \alpha}$ in cattle (Schams and Berisha, 2004; Siqueira et al., 2009). Although luteolysis is associated with a progressive reduction in luteal tissue area (Ginther et al., 2007; Herzog et al., 2010), a palpable and visually evident CL may still be observed by ultrasound imaging in the proestrus phase and as late as during behavioral estrus. Therefore, to make reliable inferences about loss of luteal function based solely on morphological evaluation, comparisons of data from serial grayscale B-mode exams (24 or $48 \mathrm{~h}$ intervals) are required.

The advent of color Doppler ultrasound imaging made it possible to examine the intensity of blood flow toward and within the CL by observing the movement of red blood cells within vessels (Acosta and Miyamoto, 2004; Ginther, 2007). In normal luteal physiology, angiogenesis is positively correlated with systemic progesterone (P4) concentrations during CL development, and apoptosis of endothelial cells is involved in both functional and structural luteolysis (Fraser and Wulff, 2003). Doppler ultrasonography, therefore, permits real-time inferences about CL functionality in different phases of the estrous cycle and has been used in cattle (Herzog et al., 2010; Bollwein et al., 2016), sheep (Figueira et al., 2015), and buffalo (Lasheen et al., 2018). Another important application for the assessment of CL blood flow (CLBF) is the early detection of nonpregnant females (Siqueira et al., 2013; Pugliesi et al., 2014; Guimarães et al., 2015). The latter approach has the potential to improve cattle reproductive efficiency by allowing earlier resynchronization of open females and, consequently, a reduction in the interval between services.

Importantly, the association between CLBF and morphology (area or diameter) increases the reliability for early prediction of pregnancy success (Pugliesi et al., 2014; Berger et al., 2017), and the incorporation of Doppler ultrasonography into routine reproductive management may aid the identification of females more likely to have pregnancy losses (Kelley et al., 2017). Consensus on the potential magnitude of these benefits of Doppler ultrasonography was not, however, reached among previous studies in cattle (Utt et al., 2009; Bollwein et al., 2016; Kanazawa et al., 2016). Perhaps the source of inconsistencies among studies lies in the fact that time points for CLBF evaluations varied between different studies, and the criteria adopted to make in- ferences about CL function by its appearance in color Doppler and B-mode imaging were sometimes divergent among studies. Nevertheless, the association of B-mode and Doppler imaging for assessing the functional status of ovarian structures may provide novel strategies for intensive reproductive management in cattle.

Because color Doppler ultrasonography has been used to identify loss of vascularization within the CL (Herzog et al., 2010), which has long been associated with loss of CL function (P4 secretion; Azmi and O'Shea, 1984; Fraser and Wulff, 2003), we hypothesize that evaluation of CLBF could be an earlier indicator of physiological luteolysis in cattle compared with evaluation of CL morphology, echotexture, or laboratory assays for P4. The objectives of this study were to (1) evaluate differences in CL features from d 12 to 20 after timed AI (TAI), and (2) determine how early changes in CLBF, morphology (size), echotexture, and function are distinguishable between prospective pregnant and nonpregnant cattle.

\section{MATERIALS AND METHODS}

Procedures described in this study were in accordance with the Brazilian Ethics, Bioethics and Animal Care Committee (CEBEA) guidelines and approved by the Embrapa Institutional Ethics in the Use of Animals Committee (CEUA, protocol CEUA-CNPGL 022011).

\section{Location and Experimental Design}

This experiment was performed in 2 replicates, within a 72-d period, from July to September (winter in the Southern Hemisphere). Holstein $\times$ Gir crossbred lactating dairy cows $(\mathrm{n}=136)$ and heifers $(\mathrm{n}=111)$ with BCS ranging from 2 to 4 (scale 1 to 5; Edmonson et al., 1989) were the study subjects. Lactating cows were 45 to $100 \mathrm{~d}$ in milk and heifers were cycling, between 18 to 25 mo of age, and with a BW ranging from 330 to $360 \mathrm{~kg}$ at the beginning of the experimental period. All females were maintained in outdoor corrals at the Embrapa Research Farm, located in Coronel Pacheco, MG, Brazil $\left(21^{\circ} 25^{\prime} 16^{\prime \prime} \mathrm{S}\right.$ and $\left.43^{\circ} 15^{\prime} 56^{\prime \prime} \mathrm{W}\right)$, had access to pasture during the night and were fed corn silage and ration during the day. Water, salt, and minerals were available ad libitum.

Females were synchronized using a standard TAI protocol consisting of $2 \mathrm{mg}$ i.m. of estradiol benzoate (EB; Sincrodiol $1 \mathrm{mg} / \mathrm{mL}$, Ourofino, Ribeirão Preto, SP, Brazil) and insertion of an intravaginal $\mathrm{P} 4$ device (1.0 g of P4, Sincrogest, Ourofino) on d $-10 ; 0.526 \mathrm{mg}$ i.m. of sodium cloprostenol $\left(\mathrm{PGF}_{2 \alpha}\right.$ analog; Sincrocio $0,25 \mathrm{mg} / \mathrm{mL}$, Ourofino) and $\mathrm{P} 4$ device removal on $\mathrm{d}$ 
$-2 ; 1 \mathrm{mg}$ i.m. of EB on $\mathrm{d}-1$ and TAI on d 0,52 to 54 $\mathrm{h}$ after P4 withdrawal. Semen straws were purchased from a commercial company and all TAI were performed by a single technician. Pregnancy diagnosis was performed $30 \mathrm{~d}$ after TAI by ultrasonography to visualize the embryonic vesicle and embryo heartbeat. Then, data were retrospectively analyzed based on pregnancy status; that is, pregnant versus nonpregnant females.

\section{Ultrasonography and Color Doppler Flow Imaging}

Beginning at d 12 post-TAI, the ovaries of all females were scanned for CL evaluation. Animals that did not present with a CL on d 12 (38 of 247) and 2 cows that had 2 CL were removed from the study. Thus, females with a single CL were examined by ultrasonography at 48-h intervals until d 20 (d 12,14, 16, 18, and 20). We used a portable ultrasound (MyLab30 Vet Gold; Esaote SpA, Genova, Italy) equipped with a linear-array rectal transducer, capable of creating images in B-mode (grayscale imaging) and in color-flow Doppler mapping mode (blood flow assessment). Imaging settings (gain, depth, frequency, power, focus position, frame rate) were standardized and remained unchanged for the duration of the experiment. In B-mode, transducer frequency was set to $7.5 \mathrm{MHz}$ and total gain $70 \%$, whereas for the color-flow mode, frequency was $6.6 \mathrm{MHz}$, pulse repetition frequency $1 \mathrm{kHz}$, frame rate of 23 frames/s, and minimum detectable velocity of $0.06 \mathrm{~m} / \mathrm{s}$.

Both ovaries were scanned and the location of the CL was recorded for each animal. Then, B-mode and colorflow mode short video clips (7 s duration) were stored in the internal memory of the ultrasound machine. Later, CL area and area of cavity (if present) were calculated using the internal calipers of the machine. To account for the presence of fluid-filled cavities, luteal tissue area (LTA) was calculated by subtracting the area of cavity from the CL area. As for quantitative assessment of vascularization, an image at the maximum diameter of the CL was analyzed using the ImageJ software (Schneider et al., 2012; National Institutes of Health, Bethesda, MD) to determine the area of colored pixels within the CL, an indirect estimation of CLBF. An adjusted CLBF was calculated dividing CLBF by LTA (CLBF:LTA ratio) to determine the proportion of colored pixels relative to the area of tissue. Last, we performed a quantitative assessment of CL echotexture as described by Siqueira et al. (2009). Briefly, a minimum representative area was arbitrarily selected within the luteal tissue and the brightness of each pixel composing that area $(5,184$ pixels $)$ was quantified by a custom software (Quantporo, Federal University of Vicosa, MG, Brazil) in a scale of 256 shades of gray (0 $=$ black; $255=$ white). The mean pixel value $(\mathbf{M P V})$ and pixel heterogeneity (HETER) were quantified for each CL in this experiment.

\section{Blood Samples and Progesterone Analysis}

On each day of examination, a blood sample was collected by puncture of the coccygeal vein into $4.5-\mathrm{mL}$ test tubes containing $\mathrm{K}_{3}$ EDTA (Vacutainer Systems, Becton Dickinson, São Paulo, SP, Brazil). Samples were centrifuged at $900 \times g$ for $15 \mathrm{~min}$ and the plasma was harvested and stored at $-20^{\circ} \mathrm{C}$ in $1.5-\mathrm{mL}$ Eppendorf tubes. Plasma P4 concentrations were determined using a solid-phase ${ }^{125}$ I RIA (Coat-a-Count Progesterone, Siemens Medical Solutions Diagnostic, Los Angeles, CA) at the São Paulo State University endocrine laboratory following procedures described elsewhere (Viana et al., 2013). Sensitivity was $0.02 \mathrm{ng} / \mathrm{mL}$ and inter- and intraassay coefficients of variation were 2.7 and $9.7 \%$, respectively.

\section{Statistical Analyses}

Data were analyzed retrospectively after pregnancy diagnosis $30 \mathrm{~d}$ post-TAI. The binomial variable pregnancy per AI (P/AI) was analyzed using the Fisher exact test and considered all females subjected to the TAI protocol, including those that failed to ovulate and did not have a CL on d 12. Animals were grouped according to pregnancy status (pregnant or nonpregnant) and further analysis consisted of comparisons of all variables between these 2 groups. Continuous outcome variables (LTA, CLBF, adjusted CLBF, MPV, HETER, and plasma P4) were examined for normality and homogeneity of variances using the Shapiro-Wilk and Bartlett tests. No transformation was required for these variables. Statistics was performed using PROC MIXED of SAS (SAS Institute Inc., Cary, NC) with a repeated statement to account for measurements over time (d 12, 14, 16, 18, and 20 post-TAI). The statistical model included animal, pregnancy status, replicate, and day of the cycle as class variables, with animal within pregnancy status and replicates as random variables. All outcome variables were analyzed for the main effects of pregnancy status, day of cycle, and their interaction. Preliminary statistical analysis indicated that animal category (heifer vs. cow) did not affect any variable included in the statistical model; therefore, all data presented here were analyzed using combined data from cows and heifers.

Because partial results demonstrated that the earliest deviation in CL features between pregnant and nonpregnant females occurred on d 16, we further examined data from d 16 separately for all continuous variables and determined cutoff values at the 25th, 50th and 
75th percentiles, dividing distinct CL features of each animal into quartiles $(\mathbf{Q}) 1$ to $4(1=$ lowest values; 4 $=$ highest values) The risk of pregnancy $(\mathrm{P} / \mathrm{AI})$ within each quartile was analyzed using the Chi-squared test to determine differences in $\mathrm{P} / \mathrm{AI}$ among quartiles. In addition, we analyzed the likelihood of pregnancy within each quartile as follows: Odds of pregnancy = $P(1) / P(0)$, where $P(1)$ is probability of being pregnant (number of pregnant/total number of animals in a given quartile) and $P(0)$ is probability of not being pregnant (number of nonpregnant/total number of animals in a given quartile). If a statistical difference was detected in $\mathrm{P} / \mathrm{AI}$ between 2 given quartiles, we calculated the odds ratio (OR) by dividing odds of pregnancy in one quartile by odds of pregnancy in the other. Finally, to determine optimal cut-off values for each endpoint at $\mathrm{d} 16$, we performed receiver operating characteristic (ROC) analyses using the GraphPad Prism 8 software (GraphPad Inc., San Diego, CA). A ROC curve was created and the area under the curve (AUC), specificity (Sp), sensitivity (Se), and $P$-values of the ROC analysis were calculated for each outcome variable. We also determined optimal cutoff values at $\mathrm{d} 16$ that were most predictive of pregnancy status.

Additionally, we determined the occurrence of abnormally short, normal, and long estrous cycles among nonpregnant animals (i.e., those that were bred but did not become pregnant and came back into estrus). For that, we arbitrarily determined that a plasma P4 $\leq 1.0 \mathrm{ng} / \mathrm{mL}$ meant occurrence of functional luteolysis (i.e., loss of function), following the same criterion previously adopted by others (Siqueira et al., 2013; Ferraz Junior et al., 2016; Liu et al., 2018). Finally, data from animals bred, not pregnant, with luteal phases that ended ( $\mathrm{P} 4 \leq 1.0 \mathrm{ng} / \mathrm{mL}$ ) before or on d 20 (short and normal length; $\mathrm{n}=46$ ) was analyzed using PROC MIXED of SAS, with a repeated statement to account for the main effect of day of cycle upon each continuous variable described previously. For this analysis, d 0 was considered the day that plasma $\mathrm{P} 4$ reached its nadir $(\leq 1.0 \mathrm{ng} / \mathrm{mL})$ and, thus, data from $\mathrm{d}-2,-4,-6$, and -8 relative to $\mathrm{P} 4$ nadir were assessed. Comparisons among means from different days relative to luteolysis were performed using the Tukey-Kramer post hoc test. Statistical significance was determined based on a $P$ value of 0.05 , and results are shown as least squares means \pm standard errors of the mean, unless otherwise stated.

\section{RESULTS}

Of all animals submitted to TAI, $15.4 \%$ (38 of 247) did not present with a CL at the ultrasound examination on $\mathrm{d} 12$; that is, ovulation rate in response to TAI protocol was $84.6 \%$ (198 of 247). We therefore removed females without a CL on d 12 from further analysis. Additionally, we excluded from data analysis 3 animals that developed cystic ovarian disease during the experiment and 8 animals with plasma $\mathrm{P} 4<1.0 \mathrm{ng} / \mathrm{mL}$ on $\mathrm{d}$ 12. Overall $\mathrm{P} / \mathrm{AI}$ was $42.1 \%$ (104 of 247 ). In the end, 198 females contributed with data on d 12 to 20 (104 pregnant and 94 nonpregnant).

Temporal analysis of CL morphology revealed that LTA remained constant from d 12 to 18, followed by a significant reduction of LTA in nonpregnant animals on d 20 (Figure 1A; $P<0.0001$ ). In addition, we observed an effect of day on plasma $\mathrm{P} 4$ concentrations $(P<$ 0.0001 ) and a significant decrease in nonpregnant animals on d 18 and 20, compared with pregnant females (Figure 1B; $P<0.0001$ ). Quantification of colored pixels as an indicator of vascularization (CLBF) revealed that pregnant and nonpregnant cattle had similar values of CLBF on d 12 and 14, but diverged from d 16 onward; that is, blood flow was increased in pregnant animals simultaneously with a decrease in nonpregnant animals (Figure 1C; $P<0.0001$ ). Similarly, the CLBF:LTA ratio (adjusted CLBF) did not change on d 12 and 14, but the values for pregnant and nonpregnant females differed from d 16 onward (Figure 1D; $P<0.0001$ ). It is noteworthy that the magnitude of differences in CLBF and adjusted CLBF increased progressively over time (d 16, 18, and 20; Figures 1C and 1D). As for CL echotexture, MPV was not affected by pregnancy status $(P>0.10)$, except on $\mathrm{d} 18$, when pregnant animals had a greater MPV than nonpregnant (Figure 1E; $P$ $=0.0228)$. Finally, HETER increased from d 12 to 20 (day effect, $P<0.0001$ ) and was affected by pregnancy status $(P=0.0391)$; that is, it had higher values in pregnant than in nonpregnant females on d 20 (Figure $1 \mathrm{~F})$.

We observed that the amount of blood flow to the CL on d 16 post-TAI was an early predictor of loss of CL function because it preceded the divergence in plasma $\mathrm{P} 4$. Therefore, we considered d 16 of the cycle a decisive moment for CLBF between animals that eventually became pregnant or not and further divided values of various CL features into quartiles and analyzed risk of pregnancy $(\mathrm{P} / \mathrm{AI})$ within quartile on that day. We observed an increase in the risk of pregnancy from Q1 to Q4 for CLBF and adjusted CLBF (Figure 2C and 2D), whereas lower or higher values for LTA did not affect the risk of pregnancy (Figure 2A). Females with the lowest plasma P4 concentrations on d 16 (Q1; below 25th percentile) had a significantly lower risk of pregnancy than females in Q2 and Q4 (Figure 2B; contrast $\mathrm{Q} 1$ vs. $\mathrm{Q} 2, P=0.0381$ and $\mathrm{Q} 1$ vs. $\mathrm{Q} 4, P=0.0128)$. Nonetheless, females in Q1 and Q3 for plasma P4 had similar risk of pregnancy. Risk of pregnancy did not 
differ among quartiles of echotexture features (MPV and HETER; Figure 2E and 2F).

Considering only features of d-16 CL that affected risk of pregnancy (CLBF, adjusted CLBF, and plasma $\mathrm{P} 4$ ), analyses of $\mathrm{OR}$ indicated that the likelihood of pregnancy increases in females with the highest values of CLBF (Q4) compared with Q3 (OR $=6.9,95 \% \mathrm{CI}$ : 2.1 to $22.5 ; P=0.0013$ ), $\mathrm{Q} 2(\mathrm{Q} 4$ vs. $\mathrm{Q} 2, \mathrm{OR}=9.2$, 95\% CI: 2.8 to $30.6 ; P=0.0003$ ) and Q1 (Q4 vs. Q1, OR $=32.8,95 \%$ CI: 9.6 to $112.1 ; P<0.0001)$. Similar
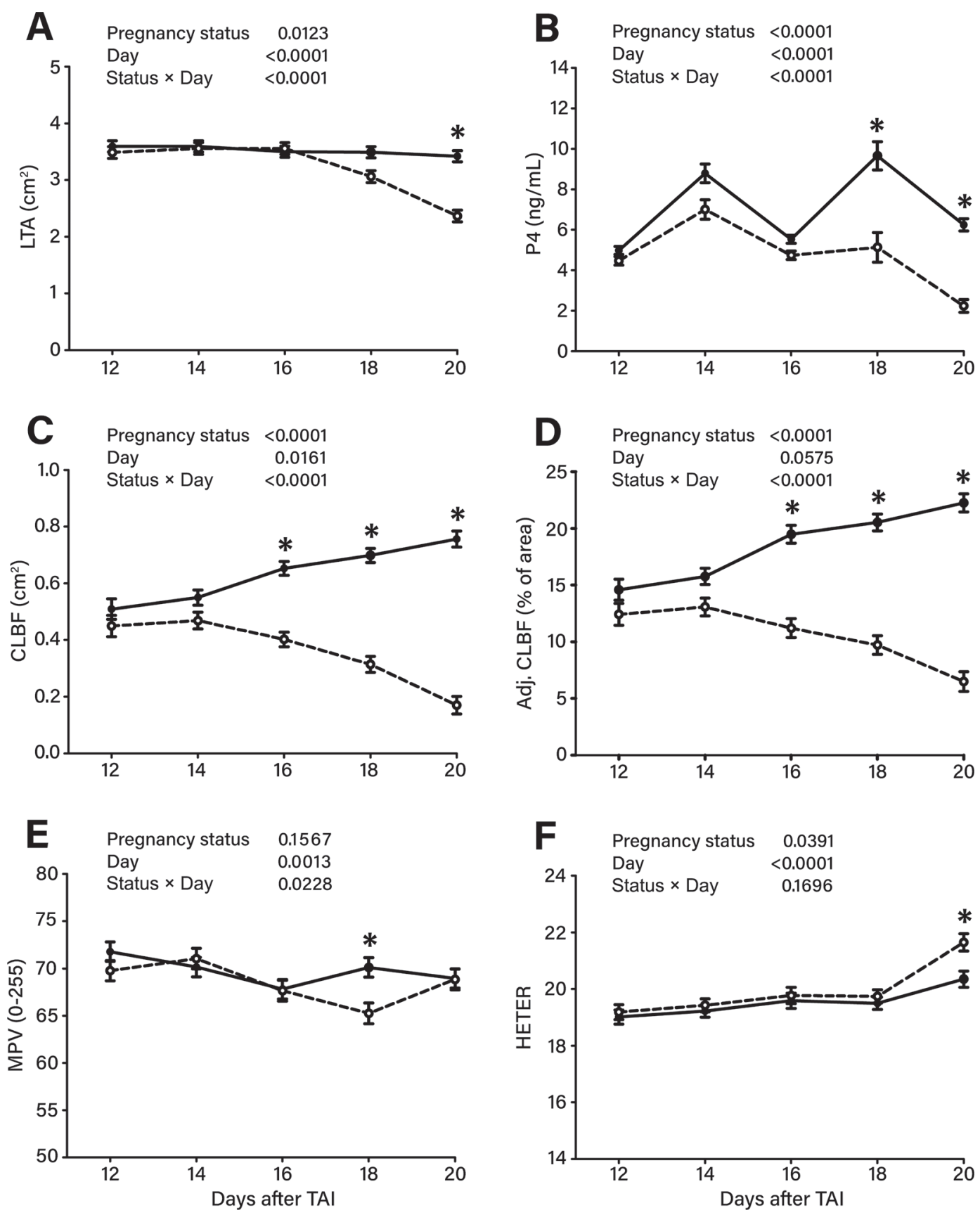

Figure 1. Features of the bovine corpus luteum (CL) from d 12 to 20 after timed AI (TAI) in females that were eventually diagnosed as pregnant (solid lines) or nonpregnant (dashed lines). Data are mean \pm SEM. (A) Luteal tissue area (LTA); (B) plasma progesterone (P4) concentration; (C) amount of blood flow to the CL (CLBF); (D) CLBF:LTA ratio (adjusted CLBF in \%); (E) mean pixel value (MPV; scale: 0 to $255)$; and (F) pixel heterogeneity (HETER). *Exact $P$-values for significant differences between pregnant and nonpregnant were LTA d 20, $P<$ 0.0001; plasma P4 d 18, $P=0.0005 ; \mathrm{d} 20, P<0.0001$; CLBF and adjusted CLBF on d 16, 18, and 20, $P<0.0001 ; \mathrm{MPV}$ on $\mathrm{d} 18, P=0.0228 ;$ HETER on d $20, P=0.0696$ 
$\square$ Pregnant $\square$ Nonpregnant

A
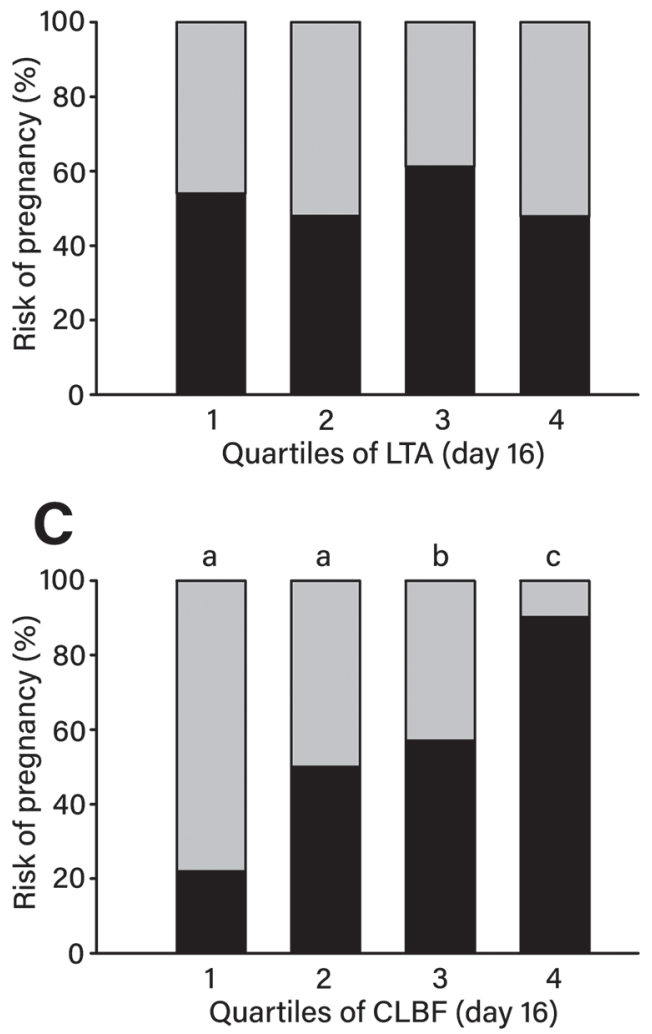

E

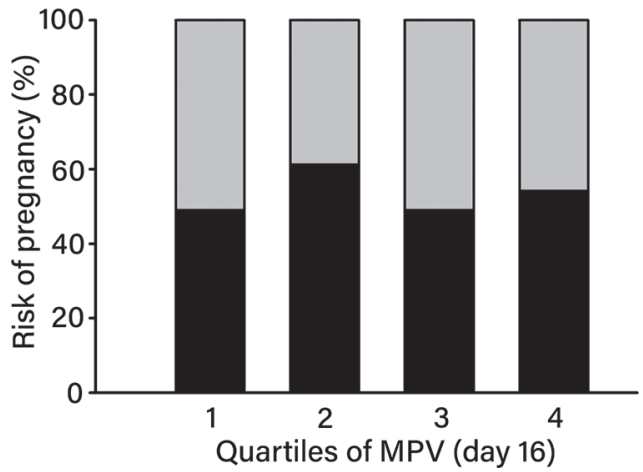

\section{B}
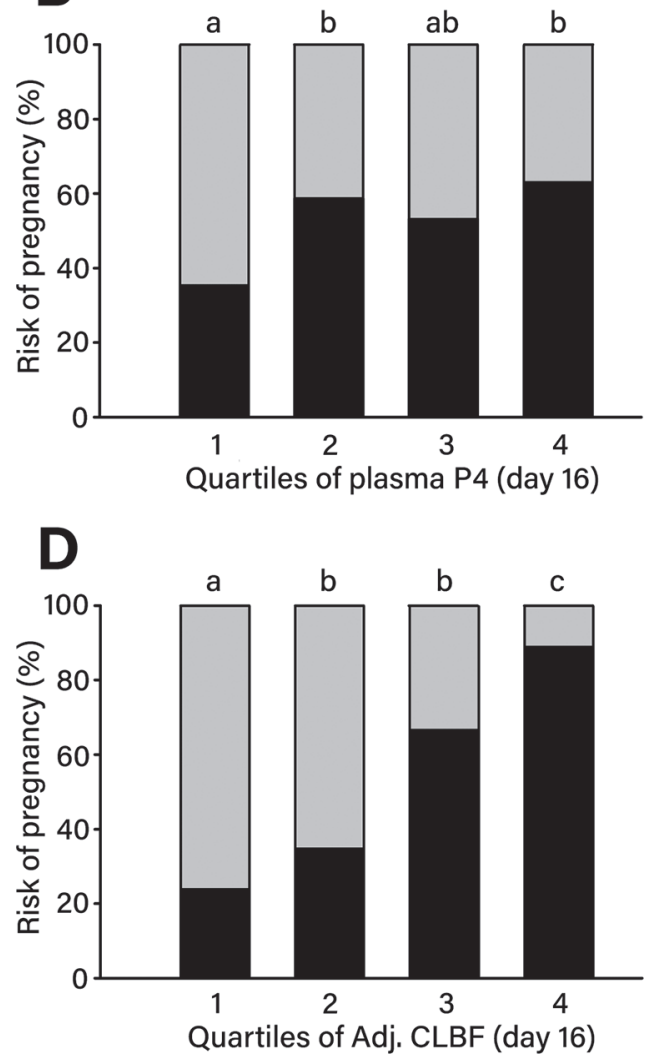

$\mathbf{F}$

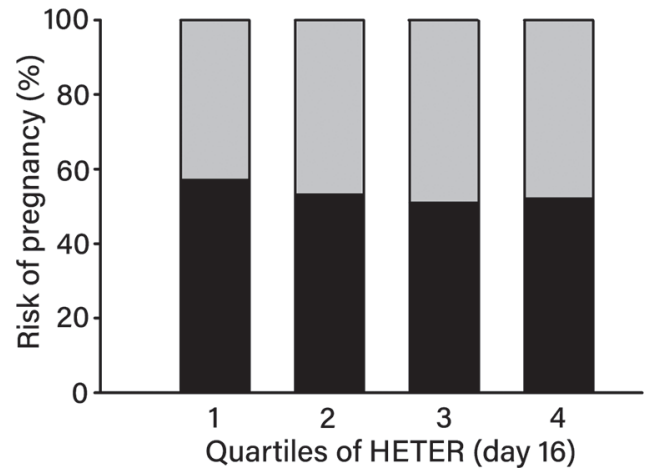

Figure 2. Risk of pregnancy in distinct quartiles calculated based on features of the bovine corpus luteum (CL) assessed on d 16 after timed AI (TAI). (A) Luteal tissue area (LTA); (B) plasma progesterone (P4) concentration; (C) CL blood flow (CLBF); (D) blood flow relative to size (ratio CLBF:LTA, adjusted CLBF); (E) CL quantitative echotexture (mean pixel value; MPV); and (F) CL quantitative echotexture (pixel heterogeneity; HETER). Females were assigned to quartiles based on low, intermediate, fair, and high values for each endpoint. Cutoff values for the 25th, 50th, and 75th percentiles, respectively, were for LTA, 3.01, 3.44, and $4.06 \mathrm{~cm}^{2}$; for plasma P4, 3.96, 5.12, and 6.34 ng/mL; for CLBF, $0.35,0.51$, and $0.67 \mathrm{~cm}^{2}$; for adjusted CLBF, 9.85, 14.54, and 19.59\%; for MPV (scale 0 to 255), 60.71, 68.30, and 74.89; for HETER, $17.70,19.35$, and 21.27 .

findings were observed for adjusted CLBF (Q4 vs. Q3, $\mathrm{OR}=4.0,95 \%$ CI: 1.3 to $12.2 ; P=0.0150 ; \mathrm{Q} 4$ vs. Q2, $\mathrm{OR}=15.0,95 \%$ CI: 4.9 to $45.5 ; P<0.0001$; and Q4 vs. $\mathrm{Q} 1, \mathrm{OR}=25.4,95 \% \mathrm{CI}: 8.1$ to $80.4 ; P<0.0001)$.
Additionally, the likelihood of pregnancy increases in females with intermediate (Q2) and higher plasma P4 (Q4) compared with the lowest quartile (Q2 vs. Q1, $\mathrm{OR}=2.6,95 \%$ CI: 1.1 to $5.9 ; P=0.0251$; and Q4 
vs. $\mathrm{Q} 1, \mathrm{OR}=3.1,95 \% \mathrm{CI}: 1.3$ to $7.2 ; P=0.0082$ ). Finally, results of ROC analysis (Figure 3) indicated that adjusted CLBF and CLBF were the best possible predictors of pregnancy at d $16(\mathrm{AUC}=0.81$ and 0.78 , respectively; $P<0.0001$ ), whereas plasma $\mathrm{P} 4$ was a fair predictor $(\mathrm{AUC}=0.61 ; P=0.0076)$, and LTA (AUC $=0.52 ; P=0.58), \mathrm{MPV}(\mathrm{AUC}=0.51 ; P=0.87)$, and HETER $(\mathrm{AUC}=0.52 ; P=0.59)$ were poor predictors of pregnancy status if assessed at d 16. Optimal cutoff values were $>15.68 \%$ of adjusted CLBF (Sp $84 \%$ and Se $70 \%$; Figure 3D), $>0.55 \mathrm{~cm}^{2}$ of CLBF (Sp $79 \%$ and Se $64 \%$; Figure $3 \mathrm{C}$ ), and $>3.45 \mathrm{ng} / \mathrm{mL}$ of plasma $\mathrm{P} 4$ (Sp 30\% and Se 97\%; Figure 3B).

Among bred, nonpregnant females, data from a subset of females having cycles of short or normal lengths $(\mathrm{n}=46)$ were used in the analysis of CL features normalized to the time of functional luteolysis (plasma $\mathrm{P} 4$ $\leq 1.0 \mathrm{ng} / \mathrm{mL}$ ); that is, days relative to luteolysis ( 0 , luteolysis; $-2,-4,-6$, and -8 ). Within this subset of females, 2 animals had data from d 0 to $-4,18$ animals had data from d 0 to -6 , and 26 animals had data from all days ( $\mathrm{d} 0$ to -8$)$. The remaining bred, nonpregnant females (36 of 94; 38.3\%) had a long cycle; that is, plasma $\mathrm{P} 4>1.1 \mathrm{ng} / \mathrm{mL}$ at the end of the study (d 20) and did not enter the analysis with normalized P4. Data of CL features on days relative to luteolysis is shown in Table 1. All outcome variables were affected by day of cycle; that is, as the cycle advanced toward luteolysis, CL features (area, blood flow, echotexture, and function) underwent significant changes.

\section{DISCUSSION}

In this study, we demonstrated that the blood supply of the bovine CL deviates between prospective pregnant versus nonpregnant females as early as at d 16 after TAI, 24 to $48 \mathrm{~h}$ before any divergent values could be identified in other CL morphological and functional features. Moreover, we detected a noticeable progressive decrease of CL blood flow from d 16 onward in animals that eventually did not become pregnant, which seems to be a reliable indicator of functional luteolysis. The occurrence of luteolysis is the primary physiological indicator of failure in maternal recognition of pregnancy (Bazer et al., 1991; Mann et al., 1999), and Doppler imaging appears to be a suitable tool to study CL regression at early time points, whereas examinations of other CL features do not seem as useful for that purpose.

Our findings corroborate the current knowledge about the physiological mechanisms of luteolysis; that is, lack of vascular perfusion halts $\mathrm{P} 4$ secretion and follows degradation and regression of the luteal tissue (Plendl, 2000). We also confirmed that the initial signs of pregnancy failure and early events leading to CL lysis may be detected as early as $16 \mathrm{~d}$ post-TAI if the right tool is used, an approach that can be of great advantage for aggressive management strategies that use intensive resynchronization schedules to improve reproductive performance (Pereira et al., 2013; Kelley et al., 2016).

Interestingly, we observed a progressive increase in CLBF during the experimental period in pregnant females. This finding is reminiscent of reports indicating a similar increase in uterine blood flow (Honnens et al., 2008) and CLBF (Herzog et al., 2011) during the first weeks of pregnancy in the cow. Earlier studies indicated that uterine blood flow increased in the gravid uterine horn during early pregnancy, probably in response to the presence of the conceptus (Ford et al., 1979). Consequently, blood supply of the ovary bearing a CL increased via existing anastomoses between uterine and ovarian arteries (Ford and Chenault, 1981). Molecular mechanisms involved in the increase in CLBF in pregnant cows remain unclear, but we speculate that they may involve the expression of growth factors (e.g., vascular endothelial growth factor, VEGF) and luteotropic molecules secreted by the conceptus. In humans, rodents, and some primates, angiogenesis increases in early pregnancy in response to prolactin (rodents) or chorionic gonadotropin (primates and humans), but this pattern was not observed in marmosets (reviewed by Fraser and Wulff, 2003). Further studies are required to determine which factors are involved in the increase of CLBF in pregnant cattle.

The physiology of post- $\mathrm{PGF}_{2 \alpha}$ events has been well described in ruminants. It involves a reduction in angiogenic activity within the CL, a decrease in blood flow to the gland, and, consequently, death of large and small steroidogenic luteal cells, followed by tissue degradation (Pate, 1994; Niswender et al., 2000). Because of this timely, orchestrated sequence of events, a temporal difference between functional and morphological luteolysis occurs in cattle (Siqueira et al., 2009; Herzog et al., 2011). The use of B-mode ultrasonography to monitor CL development and regression is, consequently, an approach of limited usefulness due to its ability to detect CL regression only a couple of days after CL function has already been lost and plasma P4 has decreased to basal levels (Herzog et al., 2010).

The outcomes of the current study suggest an alternative approach to overcome this bottleneck if we consider that the evaluation of CLBF by Doppler ultrasonography may anticipate, by 24 to $48 \mathrm{~h}$, the imminent decrease in plasma $\mathrm{P} 4$ levels in females that will return to estrus. Also, thresholds of CLBF and adjusted CLBF used in this study to sort females into quartiles may be used to determine the likelihood of pregnancy in a given 

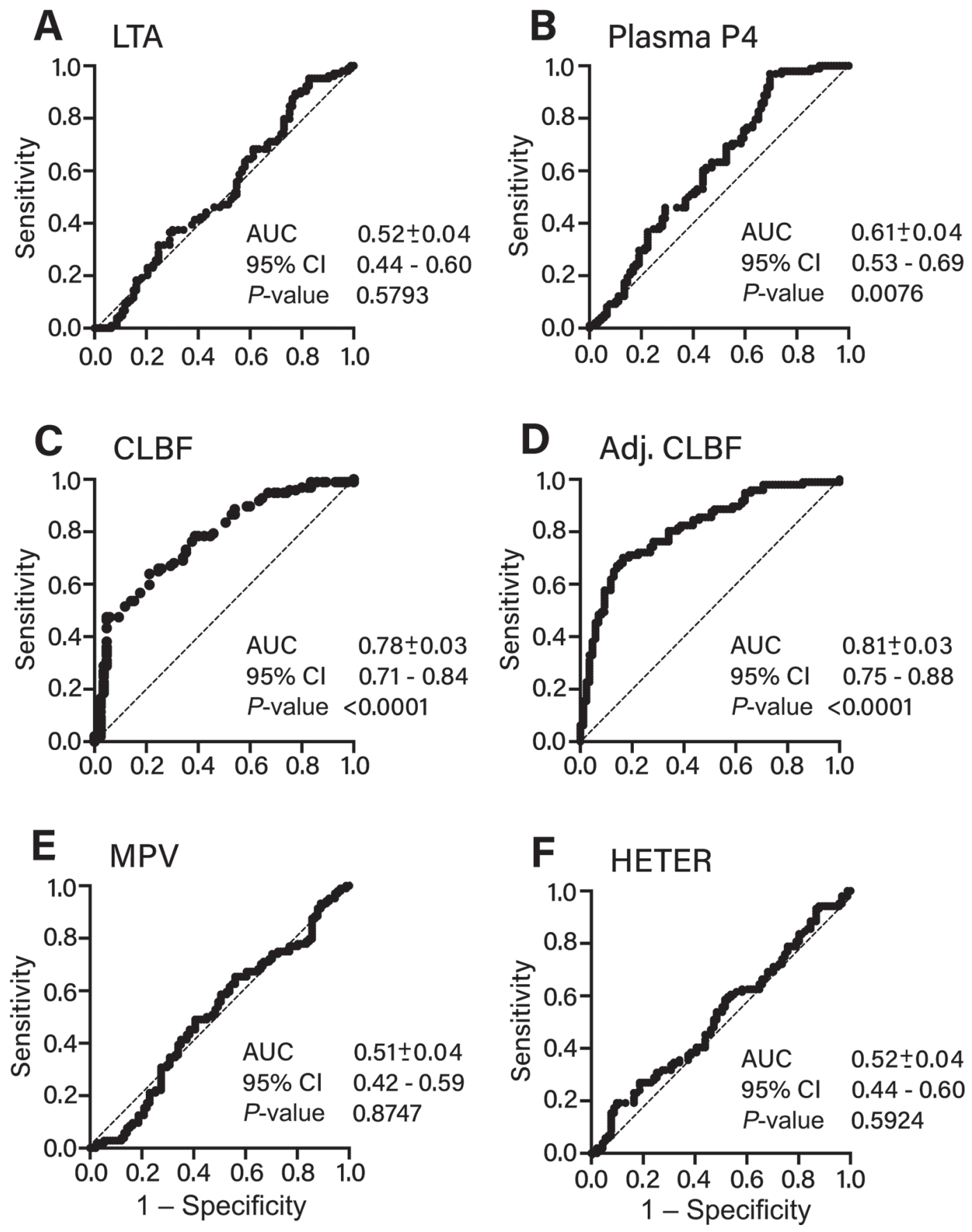

Figure 3. Receiver operating characteristic (ROC) analysis; ROC curves were calculated to determine the relationship between features of the bovine corpus luteum (CL) assessed on d 16 after timed AI (TAI) and pregnancy status. (A) Luteal tissue area (LTA); (B) plasma progesterone (P4) concentration; (C) CL blood flow (CLBF); (D) blood flow relative to size (ratio CLBF:LTA, adjusted CLBF); (E) CL quantitative echotexture (mean pixel value; MPV); and (F) CL quantitative echotexture (pixel heterogeneity; HETER). Area under the curve (AUC) and specificity (Sp), sensitivity (Se), and cutoff values for variables with $P<0.05$ were as follows: LTA: AUC $=0.52(P=0.58)$; Plasma P4: AUC $=0.61(P=0.0076)$, cutoff $>3.45 \mathrm{ng} / \mathrm{mL}(\mathrm{Sp} 30 \%$ and Se $97 \%)$; CLBF: AUC $=0.78(P<0.0001)$, cutoff $>0.55 \mathrm{~cm}^{2}($ Sp $79 \%$ and Se $64 \%)$; adjusted $\mathrm{CLBF}: \mathrm{AUC}=0.81(P<0.0001)$, cutoff $>15.68 \%(\mathrm{Sp} 84 \%$ and $\mathrm{Se} 70 \%)$; MPV: $\mathrm{AUC}=0.51(P=0.87) ;$ HETER: AUC $=0.52(P=$ 0.59). AUC data are AUC \pm SEM. 


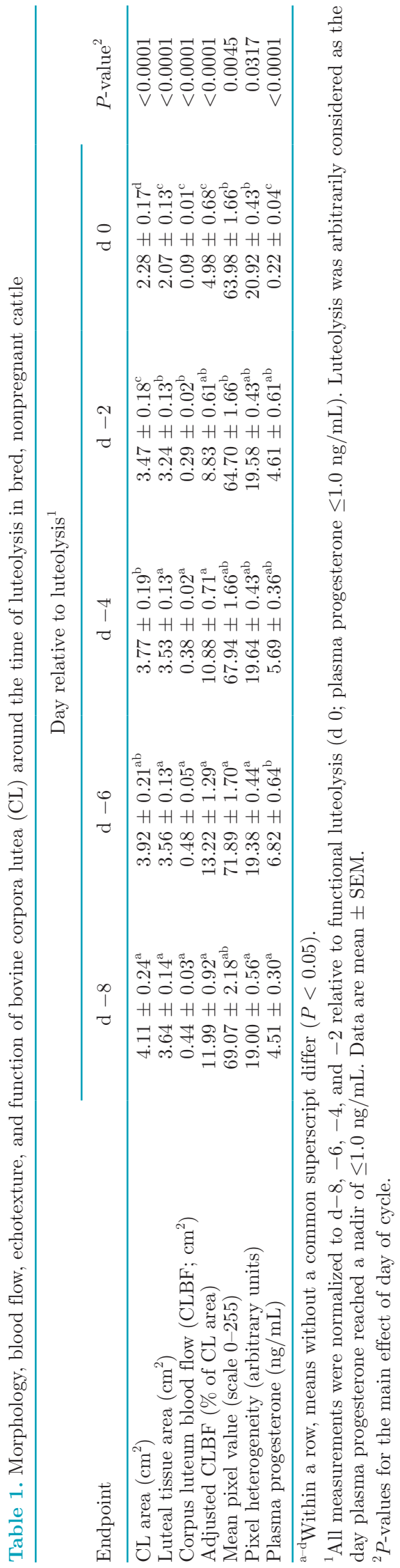

group of animals examined as early as $16 \mathrm{~d}$ post-TAI. Moreover, ROC curves were used to better explore the relationship between CL features and pregnancy status at d 16. This analysis indicated optimal cutoff values of CLBF $\left(0.55 \mathrm{~cm}^{2}\right)$ and adjusted CLBF $(\sim 16 \%)$ that may be used at d 16 with fairly high sensitivities and specificities to predict pregnancy outcome.

Quantitative assessment of image attributes (e.g., MPV and HETER) were not advantageous for early prediction of luteolysis. Pixel heterogeneity differed between pregnant and nonpregnant females on the last day of examination (d 20), later than other CL attributes. The use of computer-assisted image analysis was proposed as an alternative to optimize interpretation of sonographic images of the CL (Tom et al., 1998; Siqueira et al., 2009) and follicular wall (Singh et al., 1998; Vassena et al., 2003). Its accuracy, however, has been controversial among distinct studies (Thijssen et al., 2011; Scully et al., 2015). The lack of a consistent association between the image attribute MPV and loss of CL function was confirmed in the current study by analysis of data from nonpregnant cows, normalized to the day of luteolysis (Table 1). Mean pixel value decreased numerically as the cycle approached functional luteolysis but differences were not statistically significant. Interestingly, HETER increased significantly on the day of luteolysis compared with 8 and 6 d earlier. The increase in HETER at the time of luteolysis is a finding reminiscent of a previous report from our group (Siqueira et al., 2009). Other CL morphological and vascular features decreased consistently 24 to $48 \mathrm{~h}$ before progesterone concentrations reached values $<1.0$ $\mathrm{ng} / \mathrm{mL}$, in bred, nonpregnant females.

A secondary advantage of ultrasonographic examinations around the time of luteolysis is the early identification of females that either failed to ovulate in response to the TAI protocol ( $\sim 15 \%$ in this study) or animals that had asynchronous or short estrous cycles. For example, $3.6 \%$ (9 of 247) of the females had abnormally short cycles, with plasma $\mathrm{P} 4$ below the minimum threshold of $1.0 \mathrm{ng} / \mathrm{mL}$ on d 12 post-TAI. For those animals, Doppler imaging was useful to identify failure of timely ovulation; that is, CLBF in most females with short cycles fell into Q1 (7 out of 9) and Q2 (2 out of 9), which indicated that those animals were very unlikely to become pregnant.

An additional finding of this study was the characterization of long cycles $(\mathrm{P} 4>1.0 \mathrm{ng} / \mathrm{mL}$ on $\mathrm{d} 20)$ in a considerable proportion of animals $(38.3 \%)$ that were later diagnosed as nonpregnant at $\mathrm{d} 30$. This observation is particularly important for early diagnosis of nonpregnant animals using CLBF evaluation on d 20, as described previously by our group (Siqueira et al., 2013). That previous study demonstrated a consider- 
able incidence of false-positives, which is in accordance with the fair proportion of females with high $\mathrm{P} 4$ on d 20 observed in the present study. To overcome this limitation, CLBF evaluations may be postponed, a strategy already adopted by others (Pugliesi et al., 2018). Nonetheless, this decision of postponing CLBF exams will delay resynchronization of open females. Additionally, this would not overcome the incidence of false-positives associated with animals failing to respond to the TAI protocol; that is, that had had asynchronous ovulations. Finally, it is important to consider that some of the animals with long cycles could have been truly pregnant at the time of CLBF exams but had embryonic loss before pregnancy diagnosis at d 30, a relatively common condition in high-producing dairy herds (Wijma et al., 2016). Our results suggest that Doppler imaging for the assessment of CLBF in the mid-luteal phase is an emerging technological advance in cattle reproductive management and is expected to play an important role to improve the productivity of herds with poor reproductive performance, particularly if early identification of luteolysis is associated with early resynchronization of nonpregnant females.

\section{CONCLUSIONS}

Evaluation of bred females using Doppler ultrasonography identified divergent patterns of CLBF between pregnant and nonpregnant cattle as early as $16 \mathrm{~d}$ postTAI and anticipated the presumptive diagnosis of functional luteolysis by 24 to $48 \mathrm{~h}$, compared with the gold standard (plasma progesterone). Additionally, evaluation with color Doppler on d 16 was a reliable indicator of the likelihood of pregnancy if females were sorted into quartiles according to their quantitative CLBF and adjusted CLBF; ROC curves indicated that these 2 vascular CL features were the best early predictors of pregnancy status. In contrast, luteal tissue area and echotexture were inconsistent early indicators of luteolysis and may be used for this purpose only close to $\mathrm{d}$ 20 post-TAI. We confirmed that luteal function is lost through an evident reduction in blood flow that takes place a couple of days before any detectable changes in CL morphology and echotexture.

\section{ACKNOWLEDGMENTS}

The authors thank personnel from Embrapa's experimental farm (Coronel Pacheco, MG, Brazil) for technical assistance and animal handling. This research was supported by grants from FAPEMIG (Minas Gerais, Brazil; project CVZ APQ 02863/09) and Embrapa (Brazil; project 01.13.06.001.03.06).

\section{REFERENCES}

Acosta, T. J., and A. Miyamoto. 2004. Vascular control of ovarian function: Ovulation, corpus luteum formation and regression. Anim. Reprod. Sci. 82-83:127-140.

Acosta, T. J., N. Yoshizawa, M. Ohtani, and A. Miyamoto. 2002. Local changes in blood flow within the early and midcycle corpus luteum after prostaglandin $\mathrm{F}$ (2 alpha) injection in the cow. Biol. Reprod. 66:651-658.

Azmi, T. I., and J. D. O'Shea. 1984. Mechanism of deletion of endothelial cells during regression of the corpus luteum. Lab. Invest. $51: 206-217$.

Bazer, F. W., W. W. Thatcher, P. J. Hansen, M. A. Mirando, T. L. Ott, and C. Plante. 1991. Physiological mechanisms of pregnancy recognition in ruminants. J. Reprod. Fertil. Suppl. 43:39-47.

Berger, H., M. Lietzau, A. Tichy, and K. Herzog. 2017. Pregnancy outcome is influenced by luteal area during diestrus before successful insemination but not by milk production level. Theriogenology 104:115-119.

Bollwein, H., M. Heppelmann, and J. Lüttgenau. 2016. Ultrasonographic Doppler use for female reproduction management. Vet. Clin. North Am. Food Anim. Pract. 32:149-164.

Edmonson, A. J., I. J. Lean, L. D. Weaver, T. Farver, and G. Webster. 1989. A body condition scoring chart for Holstein dairy cows. J. Dairy Sci. 72:68-78.

Ferraz Junior, M. V., A. V. Pires, M. V. Biehl, M. H. Santos, D. M. Polizel, D. D. Nepomuceno, R. Sartori, J. B. Barreto Filho, J. R. Gonçalves, and M. L. Day. 2016. Luteolysis in Bos indicus cows on Days 5 and 7 of estrous cycle with varying doses of $\mathrm{PGF}_{2 \alpha}$. Theriogenology 86:1268-1274.

Fields, M. J., and P. A. Fields. 1996. Morphological characteristics of the bovine corpus luteum during estrous cycle and pregnancy. Theriogenology 45:1295-1325.

Figueira, L. M., J. F. Fonseca, E. Arashiro, J. Souza-Fabjan, A. Ribeiro, E. Oba, J. Viana, and F. Z. Brandão. 2015. Colour Doppler ultrasonography as a tool to assess luteal function in Santa Inês ewes. Reprod. Domest. Anim. 50:643-650.

Ford, S. P., and J. R. Chenault. 1981. Blood flow to the corpus luteum-bearing ovary and ipsilateral uterine horn of cows during the oestrous cycle and early pregnancy. J. Reprod. Fertil. 62:555-562.

Ford, S. P., J. R. Chenault, and S. E. Echternkamp. 1979. Uterine blood flow of cows during the oestrous cycle and early pregnancy: effect of the conceptus on the uterine blood supply. J. Reprod. Fertil. 56:53-62.

Fraser, H. M., and C. Wulff. 2003. Angiogenesis in the corpus luteum. Reprod. Biol. Endocrinol. 1:88.

Ginther, O. J., ed. 2007. Ultrasonic Imaging and Animal Reproduction: Color-Doppler Ultrasonography. Equiservices Publishing, Cross Plains, WI.

Ginther, O. J., L. A. Silva, R. R. Araujo, and M. A. Beg. 2007. Temporal associations among pulses of 13, 14-dihydro-15-keto-PGF2a, luteal blood flow, and luteolysis in cattle. Biol. Reprod. 76:506-513.

Girsh, E., Y. Greber, and R. Meidan. 1995. Luteotrophic and luteolytic interactions between bovine small and large luteal-like cells and endothelial cells. Biol. Reprod. 52:954-962.

Guimarães, C. R., M. E. Oliveira, J. R. Rossi, C. A. Fernandes, J. H. Viana, and M. P. Palhao. 2015. Corpus luteum blood flow evaluation on Day 21 to improve the management of embryo recipient herds. Theriogenology 84:237-241.

Herzog, K., M. Brockhan-Lüdemann, M. Kasle, N. Beindorff, V. Paul, H. Niemann, and H. Bollwein. 2010. Luteal blood flow is a more appropriate indicator for luteal function during the bovine estrous cycle than luteal size. Theriogenology 73:691-697.

Herzog, K., C. Voss, J. P. Kastelic, N. Beindorff, V. Paul, H. Niemann, and H. Bollwein. 2011. Luteal blood flow increases during the first three weeks of pregnancy in lactating dairy cows. Theriogenology $75: 549-554$.

Honnens, A., C. Voss, K. Herzog, H. Niemann, D. Rath, and H. Bollwein. 2008. Uterine blood flow during the first 3 weeks of pregnancy in dairy cows. Theriogenology 70:1048-1056. 
Kanazawa, T., M. Seki, K. Ishiyama, T. Kubo, Y. Kaneda, M. Sakaguchi, Y. Izaike, and T. Takahashi. 2016. Pregnancy prediction on the day of embryo transfer (Day 7) and Day 14 by measuring luteal blood flow in dairy cows. Theriogenology 86:1436-1444.

Kelley, D. E., K. N. Galvão, C. J. Mortensen, C. A. Risco, and A. D. Ealy. 2017. Using Doppler ultrasonography on day 34 of pregnancy to predict pregnancy loss in lactating dairy cattle. J. Dairy Sci. 100:3266-3271.

Kelley, D. E., L. Ibarbia, R. Daetz, J. H. Bittar, C. A. Risco, J. E. Santos, E. S. Ribeiro, and K. N. Galvão. 2016. Combined use of progesterone inserts, ultrasonography, and $\mathrm{GnRH}$ to identify and resynchronize nonpregnant cows and heifers 21 days after timed artificial insemination. Theriogenology 85:230-237.

Lasheen, M. E., H. M. Badr, M. M. M. Kandiel, A. M. Abo El-Maaty, H. Samir, M. Farouk, and M. H. Eldawy. 2018. Predicting early pregnancy in Egyptian buffalo cows via measuring uterine and luteal blood flows, and serum and saliva progesterone. Trop. Anim. Health Prod. 50:137-142.

Liu, T. C., C. F. Chiang, C. T. Ho, and J. P. Chan. 2018. Effect of $\mathrm{GnRH}$ on ovulatory response after luteolysis induced by two low doses of PGF2 $\alpha$ in lactating dairy cows. Theriogenology 105:45-50.

Mamo, S., J. P. Mehta, N. Forde, P. McGettigan, and P. Lonergan. 2012. Conceptus-endometrium crosstalk during maternal recognition of pregnancy in cattle. Biol. Reprod. 87:6.

Mann, G. E., G. E. Lamming, R. S. Robinson, and D. C. Wathes. 1999. The regulation of interferon-tau production and uterine hormone receptors during early pregnancy. J. Reprod. Fertil. Suppl. 54:317-328.

Niswender, G. D., J. L. Juengel, W. J. Mcguire, C. J. Belfiore, and M. C. Wiltbank. 1994. Luteal function: the estrous cycle and early pregnancy. Biol. Reprod. 50:239-247.

Niswender, G. D., J. L. Juengel, P. J. Silva, M. K. Rollyson, and E. W. Mcintush. 2000. Mechanisms controlling the function and life span of the corpus luteum. Physiol. Rev. 80:1-29.

Pate, J. L. 1994. Cellular components involved in luteolysis. J. Anim. Sci. $72: 1884-1890$.

Pereira, R. V., L. S. Caixeta, J. O. Giordano, C. L. Guard, and R. C. Bicalho. 2013. Reproductive performance of dairy cows resynchronized after pregnancy diagnosis at 31 ( \pm 3 days) after artificial insemination (AI) compared with resynchronization at 31 ( \pm 3 days) after AI with pregnancy diagnosis at 38 ( \pm 3 days) after AI. J. Dairy Sci. 96:7630-7639.

Plendl, J. 2000. Angiogenesis and vascular regression in the ovary Anat. Histol. Embryol. 29:257-266.

Pugliesi, G., G. D. de Melo, G. A. Ataíde Jr., C. A. G. Pellegrino, J. B. Silva, C. C. Rocha, I. G. Motta, J. L. M. Vasconcelos, and M. Binelli. 2018. Use of Doppler ultrasonography in embryo transfer programs: feasibility and field results. Anim. Reprod. 15:239-246.

Pugliesi, G., B. T. Miagawa, Y. N. Paiva, M. R. França, L. A. Silva, and M. Binelli. 2014. Conceptus-induced changes in the gene expression of blood immune cells and the ultrasound-accessed luteal function in beef cattle: How early can we detect pregnancy? Biol. Reprod. 91:95.
Schams, D., and B. Berisha. 2004. Regulation of corpus luteum function in cattle - An overview. Reprod. Domest. Anim. 39:241-251.

Schneider, C. A., W. S. Rasband, and K. W. Eliceiri. 2012. NIH Image to ImageJ: 25 years of image analysis. Nat. Methods 9:671-675.

Scully, S., A. C. Evans, F. Carter, P. Duffy, P. Lonergan, and M. A. Crowe. 2015. Ultrasound monitoring of blood flow and echotexture of the corpus luteum and uterus during early pregnancy of beef heifers. Theriogenology 83:449-458.

Singh, J., R. A. Pierson, and G. P. Adams. 1998. Ultrasound image attributes of bovine ovarian follicles and endocrine and functional correlates. J. Reprod. Fertil. 112:19-29.

Siqueira, L. G., V. S. Areas, A. M. Ghetti, J. F. Fonseca, M. P. Palhao, C. A. Fernandes, and J. H. Viana. 2013. Color Doppler flow imaging for the early detection of nonpregnant cattle at 20 days after timed artificial insemination. J. Dairy Sci. 96:6461-6472.

Siqueira, L. G. B., C. A. A. Torres, L. S. Amorim, E. D. Souza, L. S. A. Camargo, C. A. C. Fernandes, and J. H. M. Viana. 2009. Interrelationships among morphology, echotexture, and function of the bovine corpus luteum during the estrous cycle. Anim. Reprod. Sci. 115:18-28.

Thatcher, W. W., F. W. Bazer, D. C. Sharp, and R. M. Roberts. 1986. Interrelationships between uterus and conceptus to maintain corpus luteum function in early pregnancy: Sheep, cattle, pigs and horses. J. Anim. Sci. 62(Suppl. 2):25-46.

Thijssen, J. M., K. Herzog, G. Weijers, M. Brockhan-Luedemann, A. Starke, H. Niemann, H. Bollwein, and C. L. de Korte. 2011. Ultrasound image analysis offers the opportunity to predict plasma progesterone concentrations in the estrous cycle in cows: A feasibility study. Anim. Reprod. Sci. 127:7-15.

Tom, J. W., R. A. Pierson, and G. P. Adams. 1998. Quantitative echotexture analysis of bovine corpora lutea. Theriogenology 49:1345-1352.

Utt, M. D., G. L. Johnson III, and W. E. Beal. 2009. The evaluation of corpus luteum blood flow using color-flow Doppler ultrasound for early pregnancy diagnosis in bovine embryo recipients. Theriogenology 71:707-715.

Vassena, R., G. P. Adams, R. J. Mapletoft, R. A. Pierson, and J. Singh. 2003. Ultrasound image characteristics of ovarian follicles in relation to oocyte competence and follicular status in cattle. Anim. Reprod. Sci. 76:25-41.

Viana, J. H., M. D. Dorea, L. G. Siqueira, E. K. Arashiro, L. S. Camargo, C. A. Fernandes, and M. P. Palhão. 2013. Occurrence and characteristics of residual follicles formed after transvaginal ultrasound-guided follicle aspiration in cattle. Theriogenology 79:267-273.

Wijma, R., M. L. Stangaferro, M. M. Kamat, S. Vasudevan, T. L. Ott, and J. O. Giordano. 2016. Embryo mortality around the period of maintenance of the corpus luteum causes alterations to the ovarian function of lactating dairy cows. Biol. Reprod. 95:112.

Wiltbank, M. C., T. F. Shiao, D. R. Bergfelt, and O. J. Ginther. 1995. Prostaglandin $\mathrm{F}_{2 \alpha}$ receptors in the early bovine corpus luteum. Biol. Reprod. 52:74-78. 